\title{
Productive Transformation of Medical Clinic - Teaching Hospital, Peradeniya, Sri Lanka
}

\author{
Thilakarathna H.M.A (MBBS, MSc, MD) \\ Teaching Hospital, Peradeniya, Sri Lanka \\ DOI: 10.29322/IJSRP.11.05.2021.p11305 \\ http://dx.doi.org/10.29322/IJSRP.11.05.2021.p11305
}

\begin{abstract}
The health system is considering the patients and their wellbeing as a primary core for the function, therefore ensuring the productive patients care should be considered as a primary objective. Acknowledging the value of the patient care, while promoting and ensuring a higher standard relationship between the health employees and patients and their care givers is mainly based on strong communication and trust. While providing an effective and efficient quality care service improvement of satisfaction levels as well as institutional productivity which in turn would reduce the incidence of adverse outcomes.

The purpose of the project is to ensure provision optimized patient care by increasing quality standards and upgrading the standard of patient management accommodating the new technology and human resources in a very remarkable effective way in Teaching Hospital Peradeniya.

Action plan was proposed to introduce an appointment system for the patients with the hospital clinic of Peradeniya which contains a specific date and a time slot for each month. Current patient identification system is modified introducing a digitalized identification program. Unique patient account system is created, and each patient record book is marked with the patient specific bar code to track the process. Clinic documents are modified according to the modified system. The staff is trained to use the proposed action plan.

A literature review, Primary data analysis, key informant interviews, focus group discussions and observations were the main methods used to collect data. Expert group discussions were conducted to review the process.

Well planned patient record management system significantly improved the efficiency and effectiveness of the human and physical resources in the hospital clinic. This has improved patient's satisfaction levels. The digitalization boosted up the benefits for patients as well as care givers while providing a firm platform for a strong surveillance data which can be used in decision making process.
\end{abstract}

Index Terms- Digitalization, Medical Clinic, Peradeniya, Teaching Hospital, Transformation

\section{INTRODUCTION}

$\mathrm{Q}$ I.I Background

uality and safe delivery of health care is a growing need across the globe. Nonclinical expectation on health care has also been increased and therefore restructuring and reengineering of health systems have been warranted. The new technological advancement has created a new window to explore the impending expectations of customers and the system.

The deliverance of a patient care in a more systemized patient friendly, patient focused environment, same time ensuring the outcome of adequate patient care, has been a primary concern to the health system in the recent past [1]. The considerable advancement of the science and technology in the field of medicine change the grade of patient care in a cost effective less time consuming way. The effective patient focused and humanistic approach in providing the health care services is a major concern and upcoming challenge worldwide.

For the purpose of ensuring the sustainability of highly standardized optimized quality and safe patient care, the appropriate introduction of a standardized policy on healthcare and safety is much concerned..[5] It is well recognized that the optimization of quality standards and guidelines, Optimization of a patient focused safety orientation, 
participation of healthcare team, development of the assessment system ,auditing of standards improvement, optimization of information and organized reporting systems are expected for the achievement of a better outcome.

Quality in medical care is a multifaceted concern and is not amenable to a single outcome measure or simple metric value. Over the recent past there has been a concerted worldwide effort to optimize measurement and reporting, as well as growing consensus about the major domains of quality in medical healthcare and relevant standards and indicators to populate the above concerned domains.

Following are the key domains in concern:

- Efficiency

- Equity

- Safety

- Access and timeliness

- Effectiveness

- Patient centeredness

To ensure the achievement of quality improvement there should be standards in dividing the responsibilities, accelerated organizational development, and involvement of stakeholders in the concerned managerial system. The responsibility is to be shared and divided among the healthcare team is a mandatory contributor for undisturbed quality improvement. The outcome of high standard, patient-focused healthcare necessitates the concerted involvement and dedicated efforts of many healthcare disciplines with multidisciplinary medical professionals , with growing evidence that highly effective multidisciplinary healthcare team working in a clinical setting for a given task.

This project is primarily based on delivering a complete Quality Management via engagement and divided responsibility of all stakeholders in the internal and external source of the hospital. The project comprises with a wellstructured managerial information system to ensure the quality improvement program. It makes sure the continuous quality improvement based on application of efficient and effective policies and models, and the benchmarking of standardized healthcare practices in this institution

\subsection{Health care system in Sri Lanka}

The Sri Lankan health system comprises a mixture of Allopathic, Ayurveda, Unani as well as several other entities of medicine that works together to provide a better health outcome in this country. Considering the above specialties allopathic medicine has a vital role and is delivering most health needs of this country. The Sri Lankan health system comprises of both the state and the private sector.[2]

Currently the allopathic public health system is devolved, in accordance with the Constitution. Healthcare service delivery is managed by the central Ministry of Health and the nine provincial ministries of health.

Structure of the allopathic system is headed by the Cabinet Minister of Health. There are nine provincial ministers of health working in each province. The central ministry is responsible for national policy development related to healthcare services, recruitment and training of most of the health staff, and administration of several categories of health staff, including medical officers. The central ministry manages all teaching hospitals and most of the tertiary care hospitals. Management of secondary and PHC institutions is the responsibility of the provincial health authorities.

The central ministry currently manages about 108 healthcare institutions, which mainly function as specialist hospitals. All of the non-specialist divisional hospitals as well as primary medical care units are managed by the provincial health authorities. Policy decisions related to the health sector are the responsibility of the central ministry. It is expected that provincial ministries of health adjust their services, strategies and action plans according to the national policies and guidelines set out by the central Ministry of Health. 
Having reached many targets in quantitative aspects [4], most of the specialties in the present health system (Health administration, preventive services and curative services) is undergoing noticeable changes, mainly in the deliverance and maintenance of quality of healthcare values, within its limited resources.

\subsection{Curative care services}

In Sri Lanka the healthcare is delivered to all citizens at free of cost, which has been a national priority in the past. All the public (general) hospitals situated in major towns and cities have readily available OPD patient care unit, with laboratory and radiology specialties that are common in most. But most of the ailment has been cured in a tertiary care medical centers in such teaching hospitals in Colombo, Colombo South, Colombo North, Kandy, Peradeniya, Galle (Karapitiya Hospital) and Jaffna. The healthcare team which is comprising the multidiscipline including doctors and nurses in the government hospitals are well qualified and trained, with mainly most of the experts and experienced staff working at the teaching hospitals.[3]

Considering the low level of healthcare expenditures, Sri Lanka's health indicators are achieved potential health outcomes, comparable to more developed countries in the neighborhood

Sri Lanka's public healthcare system also has long waiting lists for specialized care and advanced procedures.

\subsection{Teaching Hospital, Peradeniya}

Teaching Hospital, Peradeniya, is one of the major three hospitals in Kandy, Sri Lanka. Established in 1980, it is major leading teaching hospitals in Sri Lanka which affiliated with the University of Peradeniya.

As well as delivering optimized medical care to patients, Peradeniya Teaching Hospital being a basement for undergraduate training programs for the medical education institutions and faculties such as faculty of Medicine, Dental Sciences and Allied Health Sciences.

The Teaching Hospital, Peradeniya is facilitating the following services such as ; surgery, pediatrics, obstetrics \&gynecology, medicine, psychiatry, orthopedics ,neonatology,toxicology, neurology, anesthesiology, pathology, microbiology, hematology, radiology, and nuclear medicine.

Peradeniya teaching hospital also consist of a fully equipped laboratory, two premature baby care unit, preliminary care unit, physiotherapy unit, EEG and EMG services, ECG department, institutional drugs store and dispensaries, diagnostic and therapeutic endoscopy unit. The hospital has a 12 bedded ICU, 03 bedded dental ICU, neonatal ICU and 4 bedded ICU at the toxicology unit. In this institution we perform 800 major surgeries per month. There are about 600 deliveries per month in the obstetric unit of this hospital.

Table 1: Basic information regarding the hospital, 2019 censes

\begin{tabular}{|l|l|l|l|l|l|}
\hline Indicator & 1st Quarter & 2nd Quarter & 3rd Quarter & 4th Quarter & whole year \\
\hline $\begin{array}{l}\text { Bed Strength (including Dental } \\
\text { hospital) }\end{array}$ & 957 & 957 & 957 & 957 & 957 \\
\hline Number of Days in the Quarter & 90 & 91 & 92 & 92 & 365 \\
\hline $\begin{array}{l}\text { Total Number of Admissions in the } \\
\text { Quarter }\end{array}$ & $\begin{array}{l}205 \\
79\end{array}$ & $\begin{array}{l}190 \\
72\end{array}$ & 202 & $\begin{array}{l}222 \\
90\end{array}$ & $\begin{array}{l}821 \\
60\end{array}$ \\
\hline
\end{tabular}




\begin{tabular}{|l|l|l|l|l|l|}
\hline In-patient Days for the Period & 709 & 675 & 701 & 738 & 282 \\
\hline $\begin{array}{l}\text { Average Percentage of Bed } \\
\text { Occupancy Rate }\end{array}$ & 98 & 36 & 28 & 41 & 501 \\
\hline Average Length of Stay & 4 & 4 & 4 & 4 & 4 \\
\hline $\begin{array}{l}\text { Average } \\
\text { Turnover }\end{array}$ & 21 & 20 & 20 & 21 & 20.5 \\
\hline
\end{tabular}




\subsection{Introduction of the Hospital Clinic Structure}

\subsubsection{Types of the clinics and human resources}

The hospital clinic services are provided by

11 clinics in total which are carried through mornings and evenings of all five days of a week and Saturday morning included.

The distribution of the human resources for the clinic is distributed as following;

- Examination of the patient is carried out by a medical officers' panel including a Consultant, Senior Registrar, Registrar and medical officers.

Other services are carried out by a nursing officers' staff, Para medic personals and a minor's staff

Figure 1: old system flowchart

After introducing the new project following modifications are made in the clinic process. They are;
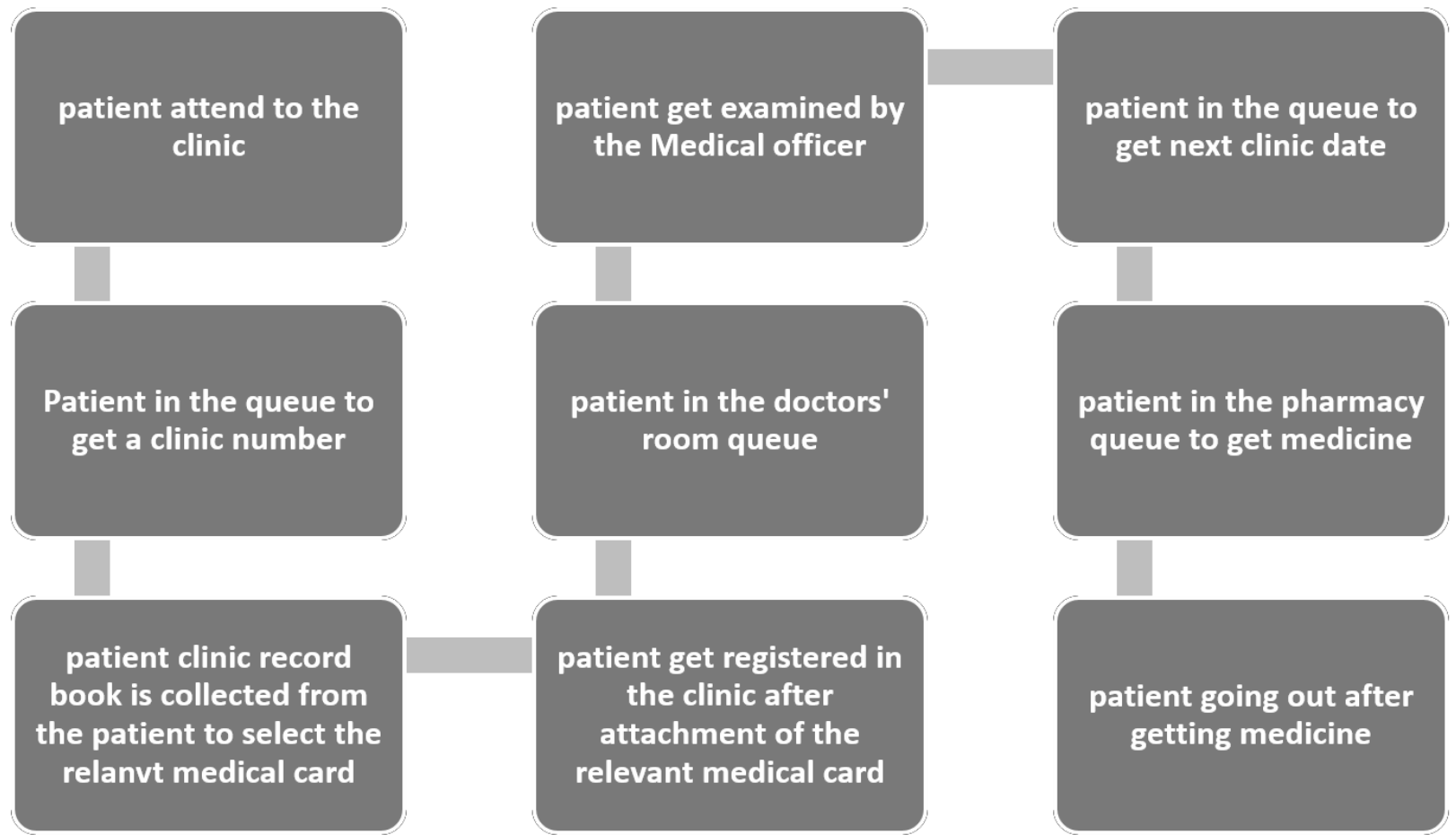

- $\quad$ Patients are categorized and given specific time slots to attend the clinic

- $\quad$ Long stand-up queues are removed

- $\quad$ Seating arrangements are provided

- $\quad$ Each seat is numbered.

The new flow chard for the process is modified as below: 

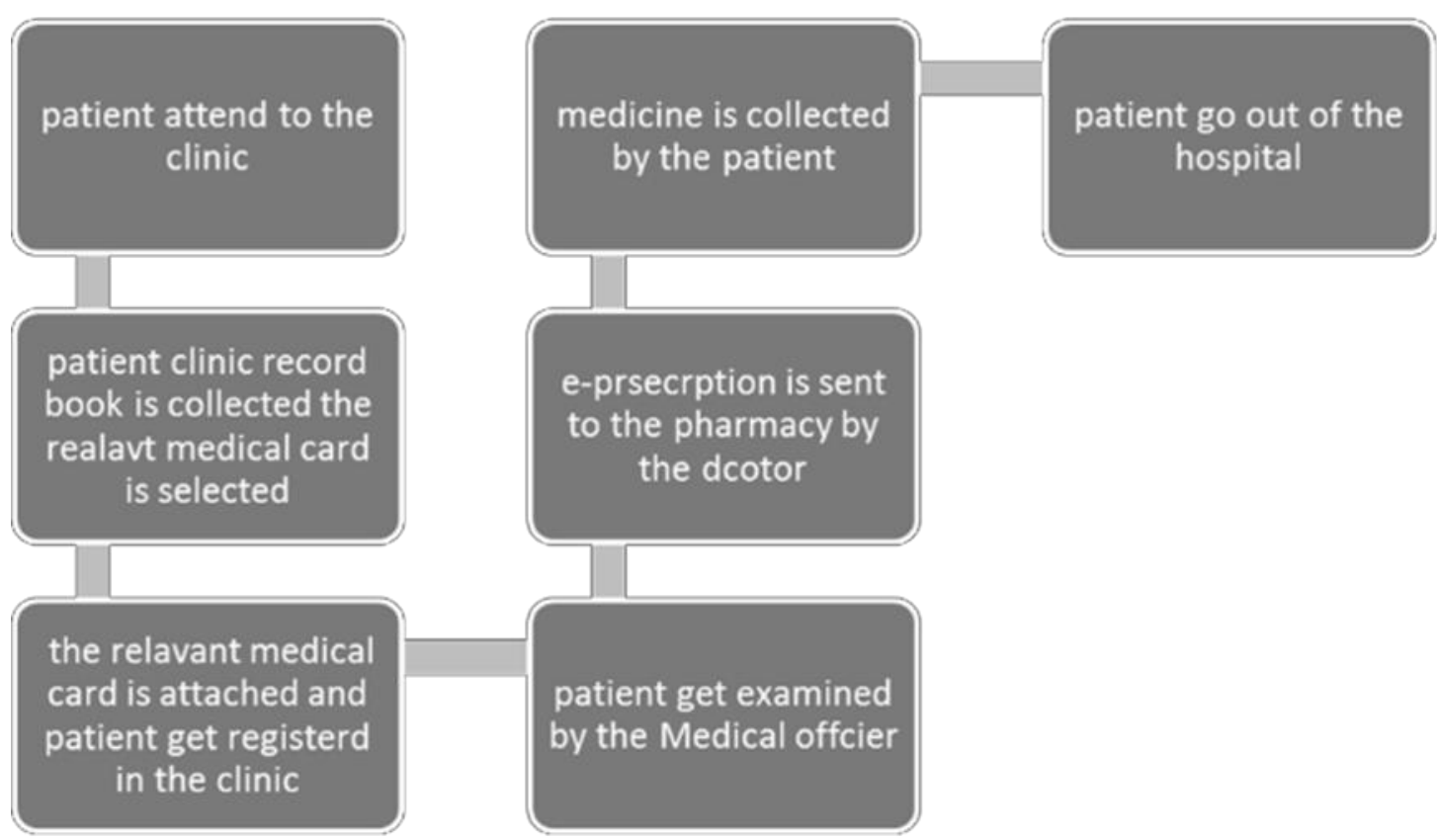

\section{Purpose of the project}




\section{Main goal}

To ensure standardized quality and effective patient care by developing quality standards and improvement of patient management with the involvement of technology and human resources efficiently in Teaching Hospital Peradeniya.

\section{Objectives}

- $\quad$ To reduce the waiting time of the patients who uses the clinic services, by $50 \%$ than the current levels

- To establish effective managerial system and processes to facilitate continuous quality improvement of the services provided in the clinic with the support of digitalization.

- To ensure organizational setting towards patient- centered care, responsive to increase patient satisfaction levels.

- $\quad$ To reduce the overcrowding at the clinic premises significantly.

\section{METHODOLOGY}

\subsection{Base line information collection (pre-test)}

A base line questioner is developed to get the specific information from the patients regarding,

- $\quad$ The patient satisfaction levels regarding the services provided by the clinics.

- Total waiting time a patient has to stay in the hospital until the services is fulfilled.

- $\quad$ Quality of patient management strategies used in the clinic.

- The patient's most preferred time range of the day to attend the clinic.

The baseline survey was conducted by the quality management unit of the teaching hospital Peradeniya. The data was recorded and analyzed.

\subsection{Expert review board discussion}

A review board is established containing the personals from each section represent the hospital clinic which has the expertise in each specific field. The board is contained with;

- Director

- Deputy Directors

- Consultants

- Medical Officers

- Nursing Officers

- Pharmacists

- Laboratory technicians

- ECG Technicians

- Radiographers

- Health Education Unit

- Quality Management unit

The information generated from the analyzed data is presented for the review board and discussed through. The changes to be made to achieve the goals are suggested and the action plan is created.

\subsection{Action plan}

2.3.1. Appointment system (part 01)

A patient appointment system is planned considering the information gathered at base line survey. Each patient is identified considering whether if he/she is an active patient or not. The active patients are divided according to the weeks of the month, the relevant clinic and given a specific time slot and a date.

The system is initialized as a pilot test for the first month of the process and continued while monitoring throughout with necessary trouble shooting actions (modifications). 


\subsubsection{Patients categorizing process}

Patients were categorized in a scientifically sound manner in order to achieve efficient and effective appointment system.

\section{Step 01:}

The medical record cards were counted and categorized into 20 numbers of slots according to the relevant year each patient is registered.

\section{Step02:}

Medical record cards of the patients who were absent for the clinics more than six months were filtered and collected.

They were categorized according to the relevant years and placed aside in labeled folders. These are inactive patients, but their records are preserved because they might continue the clinic after some time.

\section{Step03:}

The active patients' medical record cards were counted, and the total number of active patients is found.

The total number of active patients are divided into four groups considering the four weeks of a single month.

The four groups again divided into two groups labeled as group A and group B. The group A represents the patients who are set to see the relevant medical officer in their clinic and the group B represents the patients who take only prescribed medicine from the clinic.

Again, in the next month the group B is represented by the patients who are set to consultation and the group A is represented by the patients who take only prescribed medicine from the clinic. These two groups are continued interchanging their roles.

Then group A and B patients are again divided into one-hour time slots per convenience. One-hour slot in the morning includes approximately 100-120 patients. Special change is done in 11.00-12.00 am

Time slot by limiting the patient count below 100 for exceptional patients. One-hour slot in the evening include approximately 70-60 patients. Special change is done in 03.00-04.00 pm time slot by limiting the patient count below 50 for exceptional patients*.

They are:

- The patients who are about to participate for the specific one-hour time slots but failed to come around the specific time range.

- $\quad$ The patients who need to be checked by the physician each and every month.

- The patients who participate in PT/INR Blood test every month.

- The patients who need to get Benzathine Penicillin injection every month.

\subsubsection{Digitalization of the process (part 02)}

Current patient identification system is modified and utilized in the clinic process. Each patient is registered and provided an identity card including a unique barcode in each identity card.

The digitalized identity card details and the relevant barcode sticker is pasted in each patient clinic record book. Any detail relevant to the patient is stored in the digitalized system data bases using the specific barcode. 


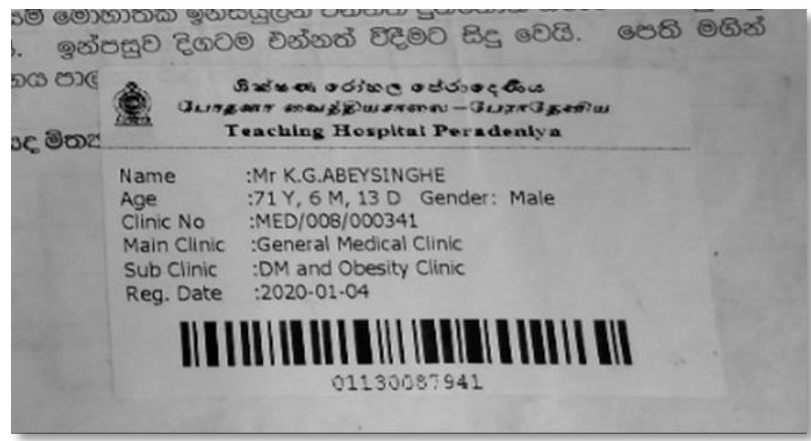

Figure 4: bar code sticker in patient record book

\subsubsection{Task allocation for the hospital staff (part 03)}

\section{Nursing staff}

- Registration of the patients.

- Issue appointments(appointment date, time and the number) for the patients.

- Mark attendance of the patients and update the total count in each clinic

- Record contact number and diagnosis of the patient

- Check up with the seating arrangements of the patients.

- Making awareness for the patients regarding new changes of the clinic

\section{Medical staff}

- Diagnose, perform check-up on the patient and insert details of the prescription into the digitalized system

\section{Minor staff}

- Collect patient record books from the patient, attach relevant medical record card of each patient and send the patient to meet the relevant medical officer.

- $\quad$ Collect patient record books from the patient, attach relevant medical record card of each patient and send them to medical officer. (After the medical officer's inspection of the patient medical record book they were given to the relevant patient)

\subsubsection{Document modification}

Patient's emergency details folder is created. It is to be used for future purpose to follow up the patient if he/she is absent for longer than two months or for any relevant reason regarding the patient.

Patient's attendance and clinic diagnosis record book is created for quick surveillance in the future.

Each patient's clinic record book is modified according to the format created considering clinic appointment details. A printed paper is attached in the patient clinic record book front page. 
Figure 5: patient clinic record book modification

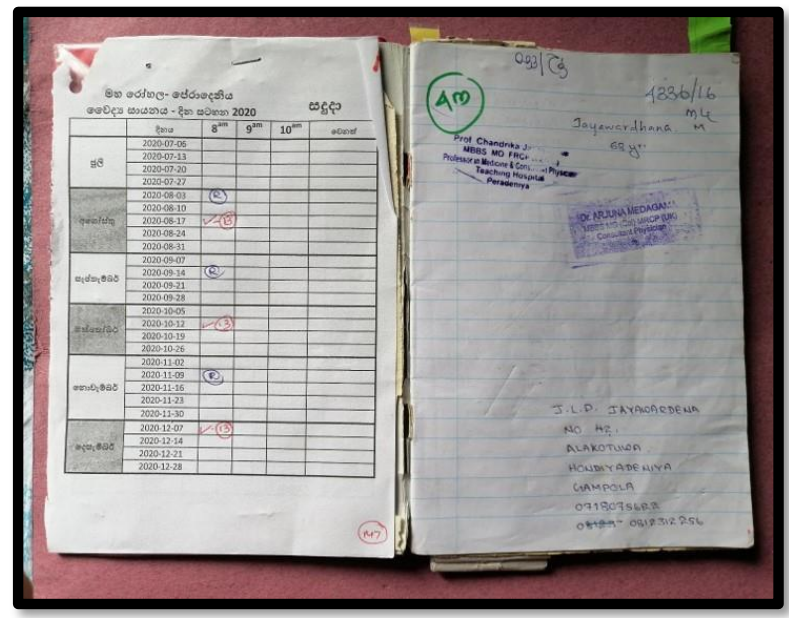




\subsection{Results evaluation (post- test)}

Post evaluation is conducted using the same questionnaire that used in the baseline survey. The data was recorded in questionnaires and then transferred in excel sheets. After analyzing the data, results were interpreted.

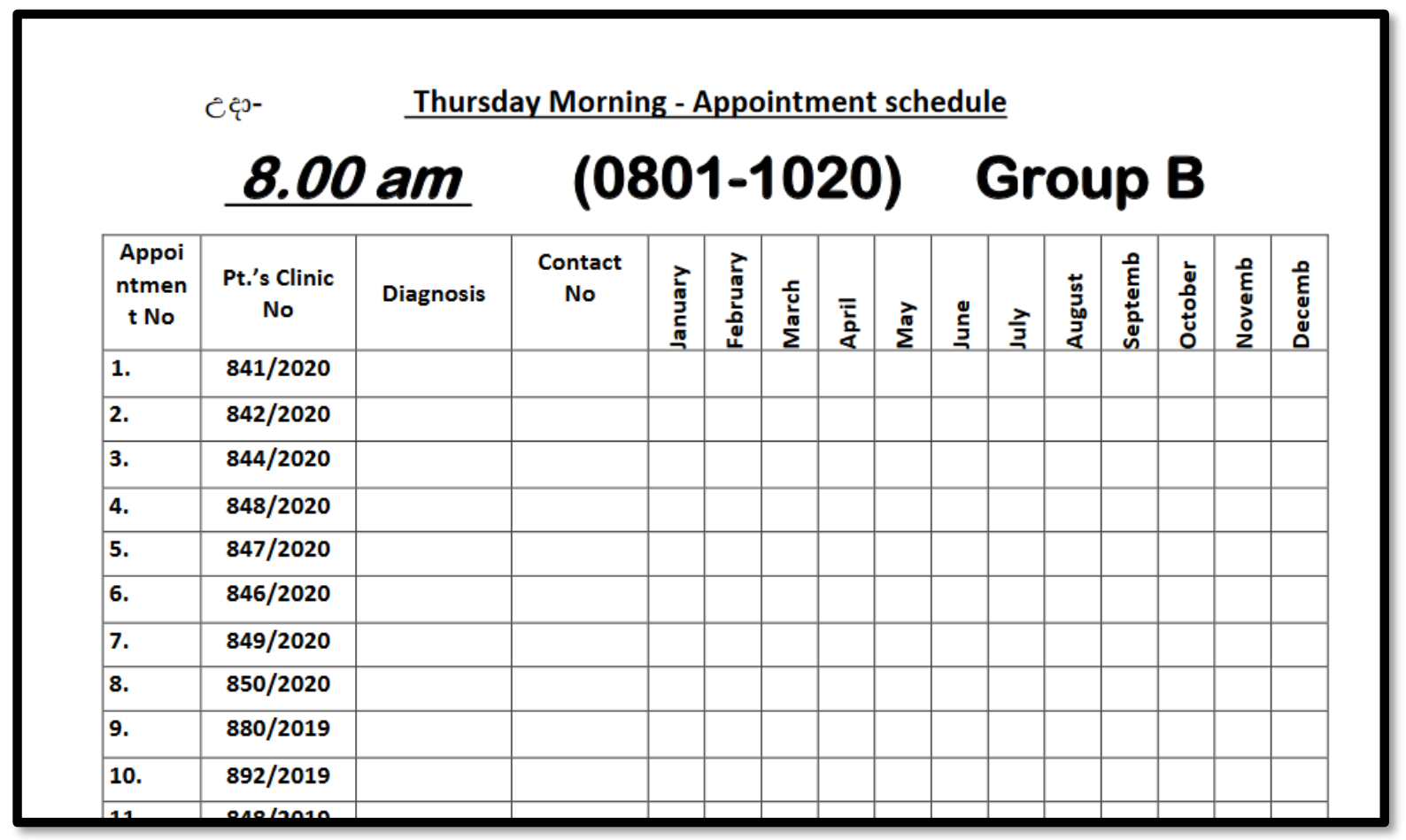

Figure 6: patient appointment schedule

\section{RESULTS}

\subsection{Survey results summary- (part 01)}

Baseline questionnaire is used to get the information regarding attitudes, experiences and suggestions of the patient about the services provided by the hospital clinic and recorded in the databases. Same questionnaire is used in the post survey after implementing the action plan. All the pre- and post-data were analyzed using epiinfo7 software which is introduced by the center for disease control and prevention, United States. Following information is extracted. 


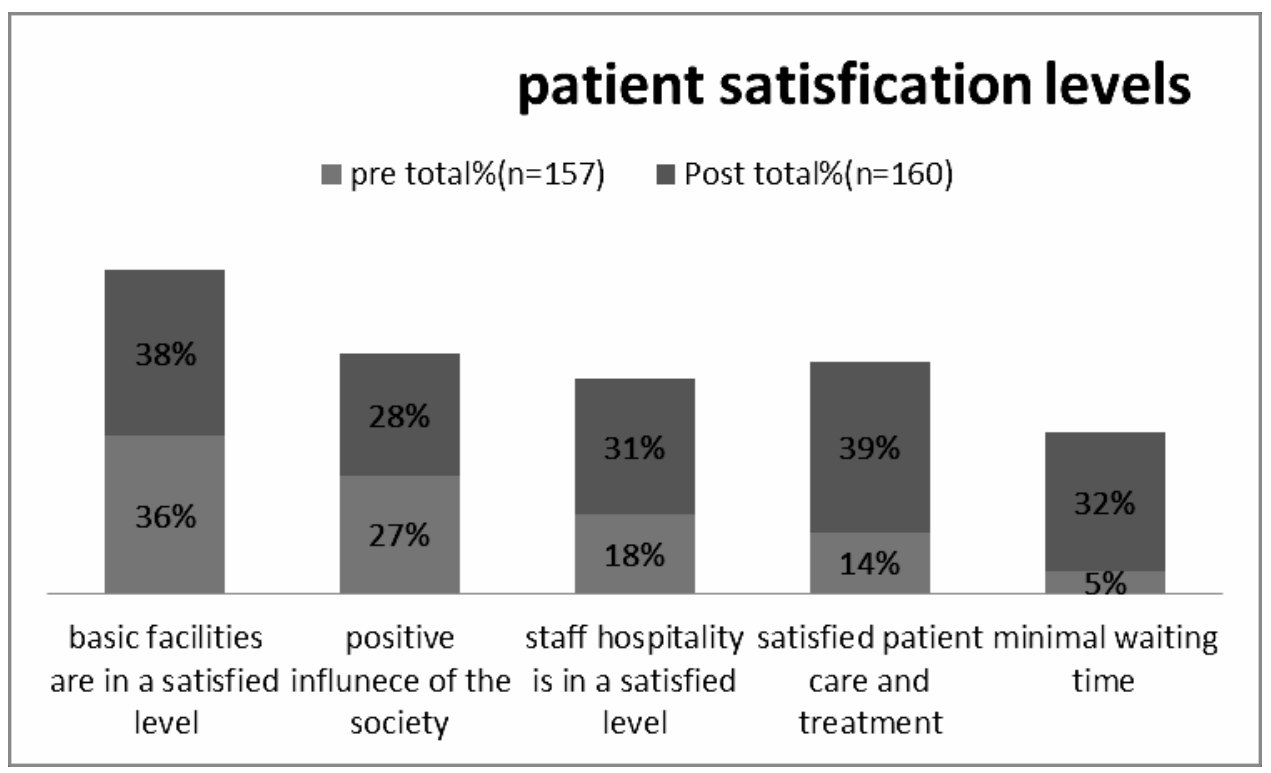

Figure 7: difference between patients' pre- and post-average waiting times in the clinic

Waiting Time (Pre), N=157

230 minutes
Waiting Time (Post), N=160

120 minutes
Difference

110 minutes
Difference Proportion

$52 \%$

Table 7: waiting time difference. 


\subsection{Survey results summary- (part 02)}

The time slots for each patient are allocated considering the patients' convenience. Following details are considered when deciding the time slot.Figure 8: reasons for choosing Peradeniya hospital.
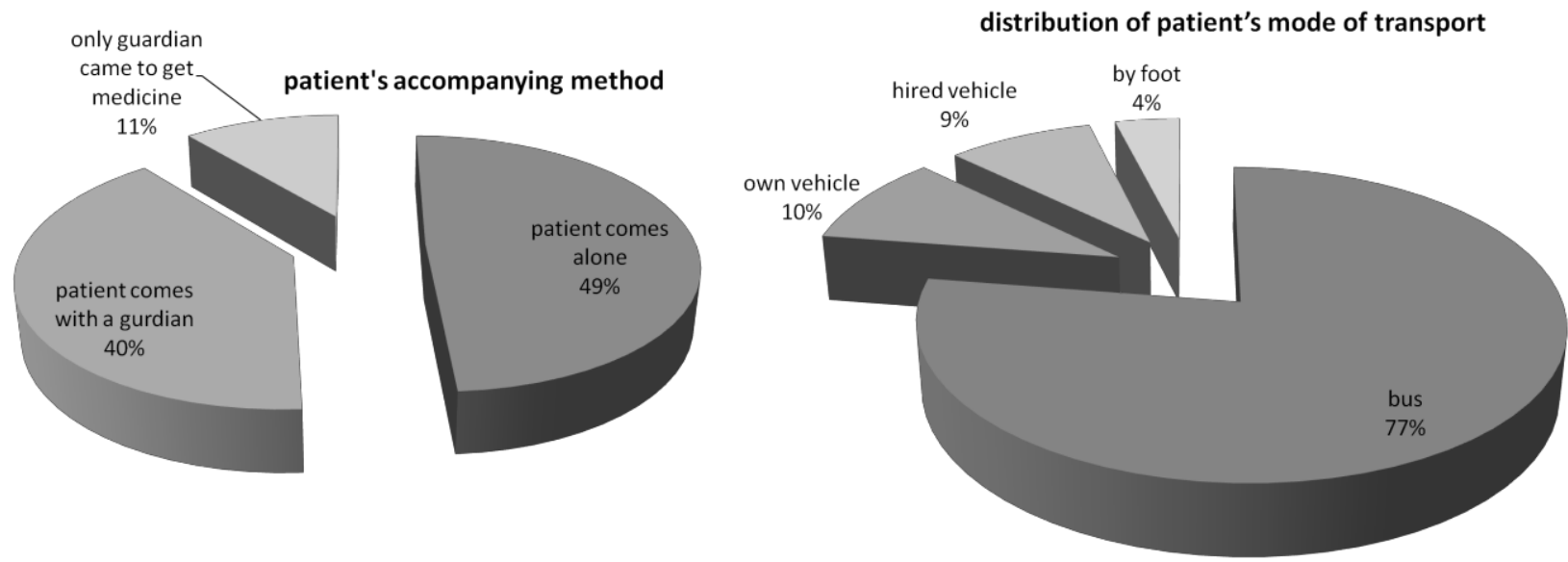

Figure 9: patients accompany method.

Majority of patients $(77 \%)$ use public transport media for their method of transportation.

Majority of patients (49\%) used to come to the clinic alone without companion whereas $40 \%$ of patients come with a bystander. Only $11 \%$ of patients do not visit clinic and get down medicines by another person.

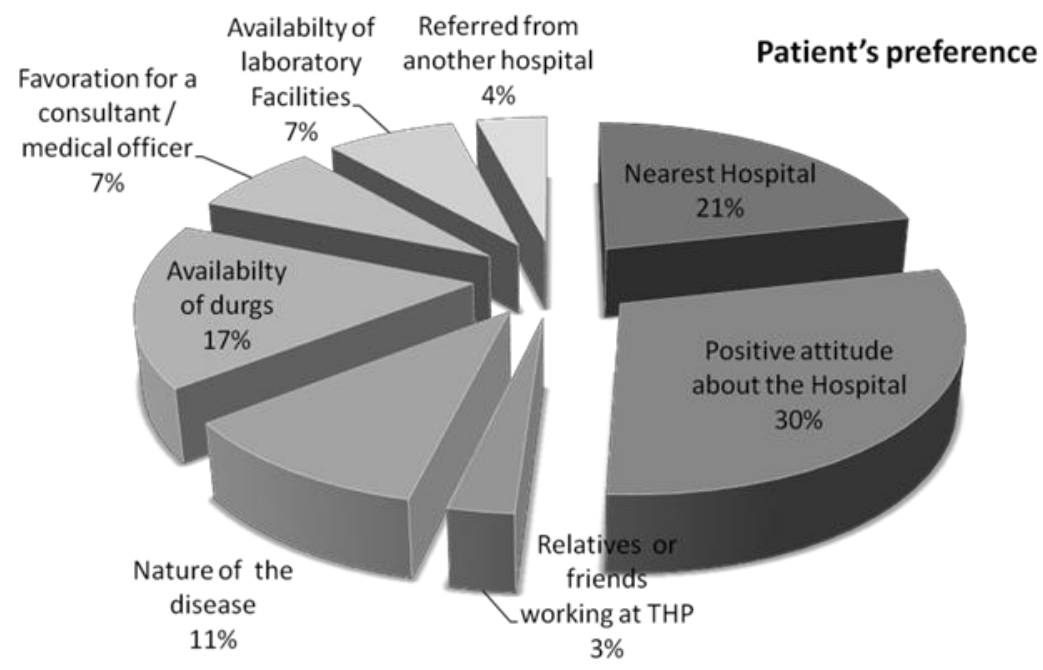

Figure 10: mode of transport of the patient 
$30 \%$ of patients have selected the THP as their treatment taking hospital because of the good name of the hospital. Being a nearest hospital was the reason for another $21 \%$ of patients

\section{DISCUSSION}

- Patient's response about patient care and treatment has been increased from $14 \%$ to $39 \%$ with a $25 \%$ of increment. (Figure 07)

- Patient's overall response about the hospitality of the staff has been increased from $18 \%$ to $31 \%$ with a $13 \%$ of increment. (Figure 07 )

These results show a clear improvement regarding the satisfaction levels of the patients at the hospital clinic. We can suggest that the changes made in the clinic by introducing an appointment system and digitalizing the process may have caused the above results.

\subsection{Justification of patient categorization}

Patients are categorized according to the steps described in the methodology section (refer, 1.3.1 patient categorization, methodology). Following information about the patient is considered when appointing a date and time. (Refer, 4.2 survey results summary-Part 02, Results section)

Most of the patients (49\%) come alone for the clinic and $40 \%$ of them are accompanied a guardian (figure 09). When a patient is accompanied by another person, they tend to prefer earlier time slots in the morning because the secondary person needs to attend his/her job after the clinic. Or else the secondary person his paid and hired to accompany the patient they prefer to finish the business as early as possible.

Majority of the patients (77\%) use buses/public transport, $10 \%$ of them use their own vehicle, $10 \%$ use a hired vehicle and $4 \%$ come by foot to attend the hospital clinic. (figure 8 ) The patients who come using hired vehicle tend to prefer earlier time slots as they have to pay less when the hired vehicle is occupied for a shorter period of time.

Some patients who use buses/public transport to attend the hospital clinic prefer different time slots according to the timetables of the public transport services.

\subsubsection{Patients' decision on selecting the teaching hospital Peradeniya (figure 10)}

Patients' preference varies from one another. $30 \%$ of them prefer teaching hospital Peradeniya because of the positive social influence, $21 \%$ says the hospital is closer with their current residence, $17 \%$ believes most of the drugs they need are available in the hospital, $11 \%$ believes the hospital suits with the nature of their disease condition,7\% says the hospital has satisfied laboratory services, $7 \%$ select the hospital because they prefer a certain medical officer/ consultant is the best fit for them and $4 \%$ of them are referred from another hospital according to the shared care system.

\subsection{Other benefits}

The measurable improvements derived from the results interpretation clearly justified the contribution of the clinic policy actions to the achievement of all the project's objectives with flying colours. However, there are some additional benefits gained from changes made in the clinic. They are:

\subsection{1 for the institution}


- $\quad$ Productivity is developed.

5.2.1.1. For the hospital staff

- Job satisfaction improved.

- $\quad$ Stress condition and exhaustion due to overcrowd management is deceased.

- $\quad$ Newly appointed members get easily trained within the system

\subsubsection{For the patients at the clinic}

- $\quad$ Exhaustion and dissatisfaction due to long queues and waiting is decreased.

- $\quad$ Time and money is saved

Patients get to meet the doctor once in two months so they can get new prescriptions accordingly without continuing the same drugs for a longer period of time as the previous system

\subsubsection{Reducing the over-crowding condition at the clinic premises}

There is a positive relationship with the improvement of patient satisfaction levels and reduction of overcrowding situation at the hospital clinic. Despite of the post evaluation questionnaire, Observations are done to have a firm idea about the over- crowding situation.

\section{CONCLUSION \& RECOMMONDATIONS}

Well planned patient record management system significantly improved the efficiency and effectiveness of the human and physical resources in the hospital clinic. This has improved patient's satisfaction levels. The digitalization boosted up the benefits for patients as well as care givers while providing a firm platform for a strong surveillance data which can be used in decision making process.

\section{REFERENCES}

[1] Cabinet Memorandum, 2015. Policy Repository -Ministry of Health -Sri Lanka National Policy on Healthcare Quality and Safety, s.1.: Democratic Socialist of Republic of Sri Lanka.

[2] Dr. Denham Pole MBBS, M., 2010. Electronic Patient Records in Sri Lankan Hospitals. [Online] Available at: http://www.mdssrilanka.com [Accessed 01 2021].

[3] M.Samarage, D., 2006. Health Care System: SRI LANKA. Geneva, Migration and Human Resources for Health: From Awareness to Action, CICG.

[4] Management Development and Planning Unit, Ministry of Health, Nutrition and Indigenous Medicine, Sri Lanka, 2018. National Health Performance Framework, colombo: "suwasiripaya".

[5] Ministry of Health, Nutrition and Indigenous Medicine, Sri Lanka, 2017. Primary health care systems (PRIMASYS): case study from Sri Lanka, Geneva: World Health Organization.

\section{AUTHORS}

First Author - Thilakarathna H.M.A (MBBS, MSc, MD), Teaching Hospital, Peradeniya, Sri Lanka 